Research Article

\title{
Seroprevalence of Human Immunodeficiency Virus infection among blood donors of central Karnataka
}

\author{
Dr. Bommanahalli BP ${ }^{1}$, Dr. Karani $A^{2}$, Dr. Umapathy KG $^{3}$, Dr. Shashikala $\mathbf{P}^{4}$ \\ ${ }^{1}$ Dr. Basavaraj P. Bommanahalli, Associate Professor, ${ }^{2}$ Dr. Anita Karani, Assistant Professor, Both are affiliated with \\ Department of Pathology, Gadag Institute of Medical Sciences, Gadag. Karnataka, ${ }^{3}$ Dr. Kavita Umapathy G, Professor ${ }^{3}$, \\ ${ }^{4}$ Dr. Shashikala P, Professor, Both are affiliated with Department of Pathology, S.S. Institute of Medical Sciences \& \\ Research Centre, Davangere, Karnataka, India
}

Address for Correspondence: Dr. Basavaraj P. Bommanahalli, Associate Professor, Department of Pathology. Gadag Institute of Medical Sciences, Gadag, Karnataka, Email ID: basupath@ rediffmail.com

\begin{abstract}
Introduction: Transfusion of blood and blood products is life saving procedure which benefits numerous patients worldwide, as transfusion of blood or its components is an integral part of medical and surgical management. At the same time it is an important route of transmission of infection to the recipients. Seroprevalence of HIV among blood donors is important mode of transmission, which can be reduced by practicing $100 \%$ voluntary donation and strict donor screening. Study was conducted to find out the seroprevalence of HIV among blood donors with respect to type of the donor, age, sex and blood group of the donor. Methodology: This study was conducted from January 2005 to December 2009 at the blood bank of tertiary care Medical College Hospital, serving people of Central Karnataka. Blood units collected from eligible blood donors were subjected to $4^{\text {th }}$ generation ELISA for screening for IgG antibodies to HIV. Prevalence of HIV infection was noted using SPSS version 13 statistical package in relation to type of donor, age, sex and blood group of donor. Significance of the trend was determined by chi square test. Result: Total of 19,413 donors were screened during the study period. Majority (94\%) of donors were replacement donors and $46.13 \%$ of donors belonged to the age group 18 to 25 years. Overall seroprevalence of HIV was $0.5 \%$. Seroprevalence was more in replacement donors as compared to voluntary donors. Conclusion: Seroprevalence detected by immunoassay testing represents only tip of the iceberg. This could be reduced by $100 \%$ voluntary blood donation.
\end{abstract}

Keywords: Blood Transfusion, Blood Donors, HIV, Seroprevalence

\section{Introduction}

A new disease was detected in 1981, which was confirmed to be caused by unique retrovirus (1984) and as the cause of acquired immunodeficiency syndrome (AIDS)in1985.HIV infection was first reported in India in a commercial sex worker in Madras, Madurai and Vellore in 1986 [1]. Total number of adults and children estimated to be living with HIV and AIDS is between 1.8 to 3.2 millions in India, according to fact sheet 2008 update. Tamil Nadu, Karnataka, Maharashtra, Andhra Pradesh, Manipur, and Nagaland are the six high prevalence states in India [2]. National AIDS Control Organization (NACO) estimates $86 \%$ transmission is due to sexual risk, $2.4 \%$ due to intravenous drug users, $2.0 \%$ due to blood and blood products, and $3.6 \%$ due to perinatal transmission. Commercial sex workers are

Manuscript received: $2^{\text {nd }}$ August 2015

Reviewed: $12^{\text {th }}$ August 2015

Author Corrected: $22^{\text {nd }}$ August 2015

Accepted for Publication: $31^{\text {st }}$ August 2015 responsible for the majority of HIV transmission in India [3]. Blood and blood products form the integral part of health care system. At the same time it is an important mode of infection to the recipients. Concealing the medical history by blood donors and limitations of screening tests pose a great threat to safe blood transfusion [4].

This study was undertaken to estimate the seroprevalence of HIV among blood donors and trend was noted with respect to type of donor, age, sex, blood group of donor.

\section{Materials and Methods}

This study was conducted in SS Blood Bank, attached to tertiary level teaching hospital of SS Institute of Medical Sciences and Research Centre Davangere from 
January 2005 to December 2009. After obtaining institutional ethical clearance from research and publication committee, blood donors were screened by targeted questionnaire and by medical examination with informed consent. Blood donors were either replacement or voluntary donors. Clinically healthy individuals of 18 to 60 years of age with body weight more than $45 \mathrm{~kg}$ and hemoglobin more than $12.5 \mathrm{~g} / \mathrm{dl}$ were qualified for donation. Sera of these qualified blood donors were screened for IgG antibodies to HIV by using commercially available (J Mitra \& Co Pvt Ltd New Delhi) Enzyme Linked Immunosorbent Assay

\section{Research Article}

(ELISA) kits of fourth generation and the procedure of test was followed according to manufacturer's instruction. The positive sera and random negative samples were retested by ELISA in Bapuji blood bank Davangere in order to assure the quality of in house by external peer.

Data were entered and analyzed by using SPSS version 13 statistical package. Prevalence of HIV-1 \& 2 was noted with respect to age, sex, type of donor, year and the blood group. Significance of the trend was determined by chi square test.

\section{Results}

A total number of 19,413 donors were screened during the study period. Of these 19,189 (99\%) were males and 224 (1\%) were females. $94 \%$ of donors were replacement donors (Figure 1) and $46.13 \%$ of donors belonged to the age group 18 to 25 years (Figure 2). The commonest blood group was $\mathrm{O}$ positive.
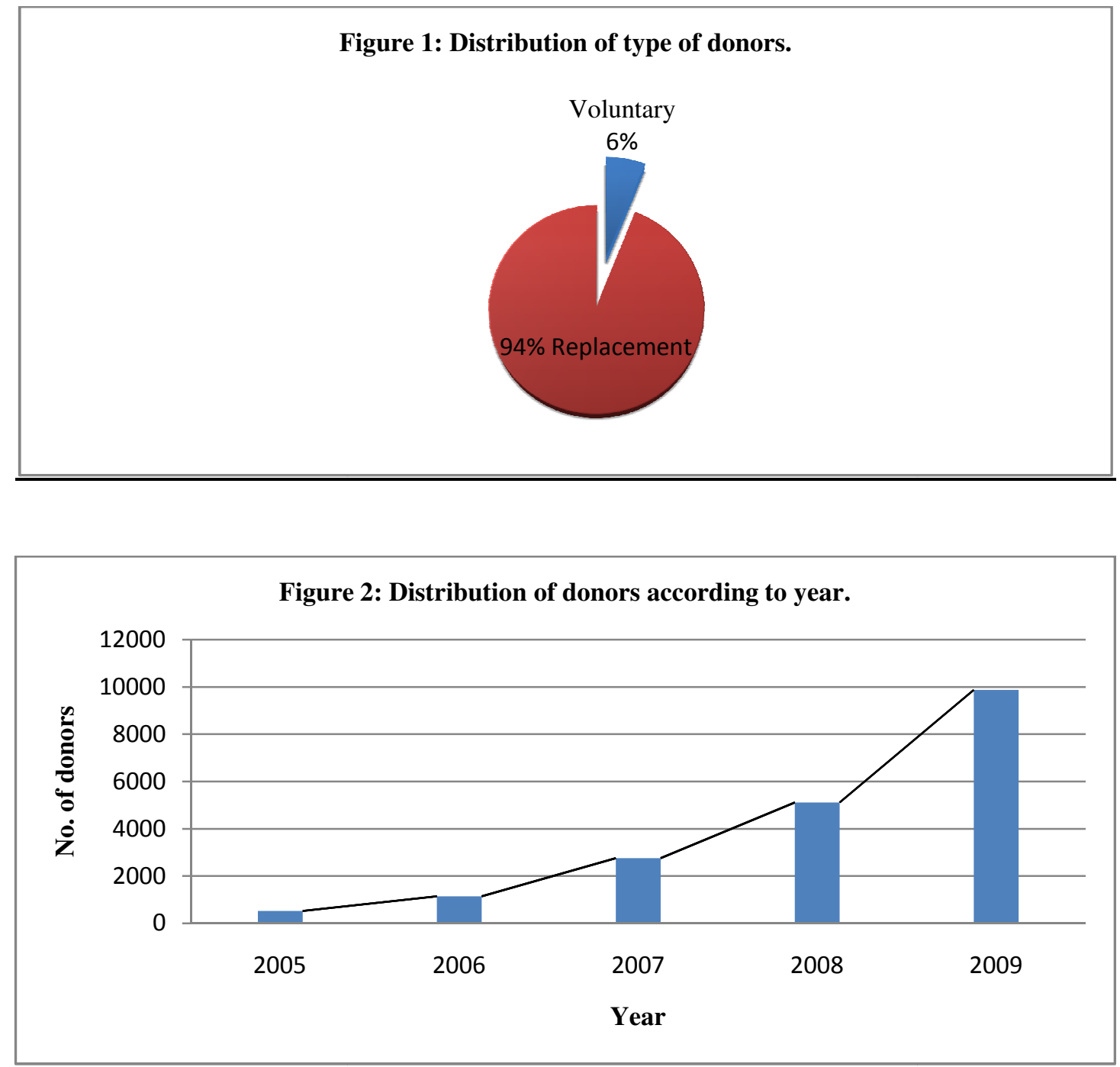

The overall prevalence of HIV-1 was $0.5 \%$ in our study. HIV-2 infection was not observed. Seroprevalence of HIV-1 in voluntary donors was $0.3 \%$ and in replacement donors is $0.5 \%$. Seroprevalence observed in males was $0.5 \%$. The majority of HIV positive cases were in the age group of 26-35 years (Table 1). The trend of HIV prevalence increased from the year 2005 to 2007 and later decreased till 2009 (Figure 3). 
Table 1: Distribution of seroprevalence of HIV according to age of donor.

\begin{tabular}{|l|l|}
\hline Age (Years) & Seroprevalence (\%) \\
\hline $18-25$ & 0.4 \\
\hline $26-35$ & 0.68 \\
\hline $36-45$ & 0.35 \\
\hline $46-60$ & 0.46 \\
\hline$p$ value $: 0.57$ Non significant & \\
\hline
\end{tabular}

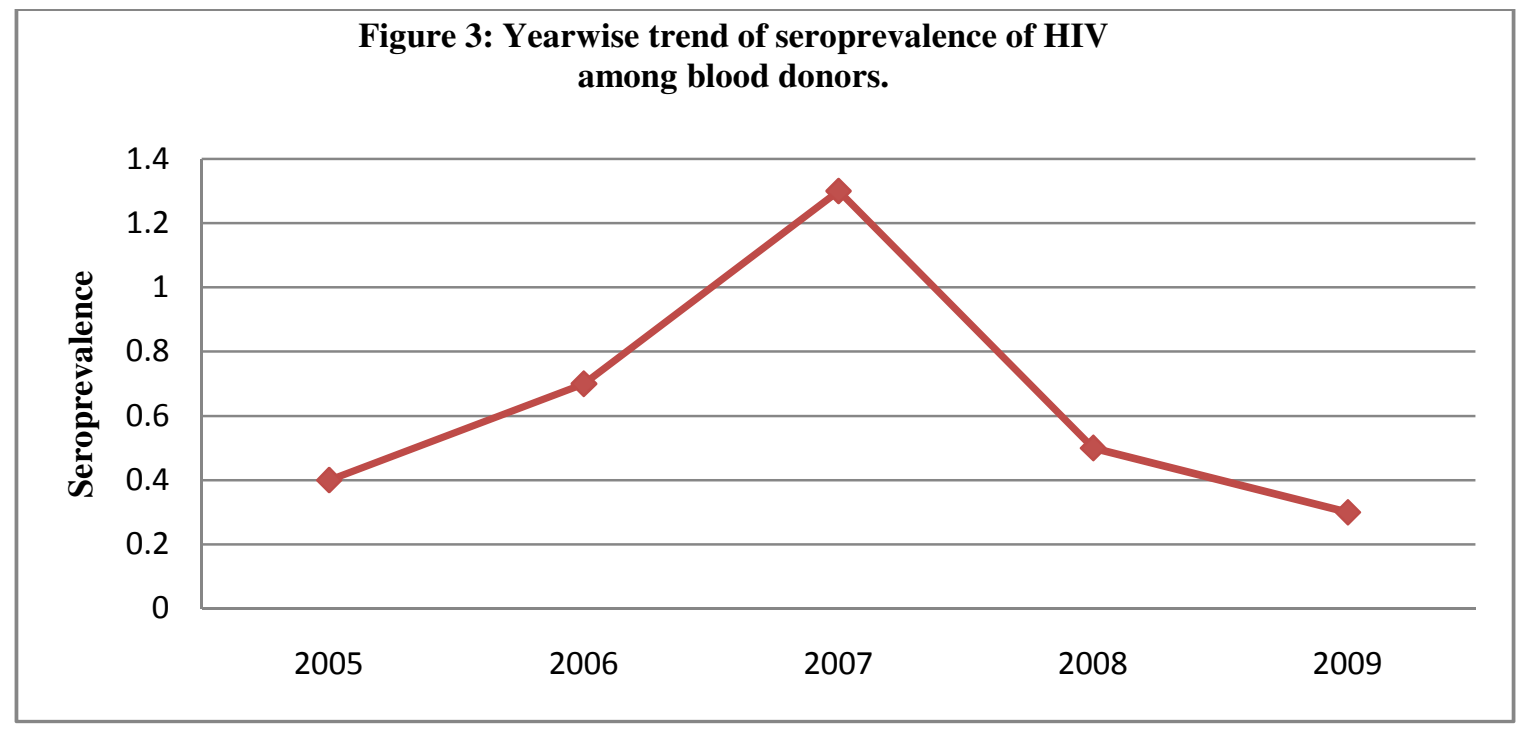

Co-infection of HIV-1 and Hepatitis B was detected in two donors and co-infection of HIV-1 and Hepatitis C was detected in one donor. All these were replacement donors. The association of HIV infection with the parameters like age group, sex, type of donor, blood group was statistically insignificant.

\section{Discussion}

There are two types of HIV infections in humans i.e. HIV-1 and HIV-2. In South Asia, the most common HIV infection observed is HIV-1. However there are significantly less number of confirmed cases of HIV-2 infection reported in India and Nepal. India has the second highest number of people living with HIV and AIDS outside Africa. According to UNAIDS country fact sheet 2008 update, the total number of adults and children estimated to be living with HIV and AIDS in India was $1.8-3.2$ million with prevalence rates for adults estimated to be within $0.2-0.5 \%$. These figures have declined when compared with data of 2003 and 2005, indicating a positive impact of prevention and control programs [2].

Blood transfusion is life-saving procedure and integral part of health care delivery system, but simultaneously it carries the $100 \%$ risk of transmitting the transfusion transmissible infections (TTI). Even after screening the blood for TTI like HIV, hepatitis B, hepatitis C, syphilis and malaria serological window period still poses a threat to blood safety because of limitations of screening tests [5].

In our study overall seroprevalence of HIV was $0.5 \%$. The seroprevalence of HIV in blood donors among different parts of India is given in the Table 2 [5-12]. Highest seroprevalence in our study was seen in the age group of 26-35 years. In our study the seroprevalence of HIV infection in replacement donors was comparatively higher than voluntary donors. The similar observation were noted in other studies $[6,9,11,12]$. In the study by Arora et al [7] none of the voluntary donors were seroreactive for HIV. The reason for higher prevalence of HIV among replacement donors could be the obligatory motto behind the donation, which might hide their disease during pre-donation clinical screening. Hence, $100 \%$ voluntary blood donation should be practiced for safe blood. 
Research Article

Table-2: Seroprevalence of HIV in blood donors in various studies

\begin{tabular}{|l|l|l|l|l|}
\hline Study & Place & Year & Sample size & Prevalence \\
\hline Giri et al [5] & Maharashtra & $2009-10$ & 5661 & 0.07 \\
\hline Pahuja et al [6] & New Delhi & $2002-05$ & 28,956 & 0.56 \\
\hline Arora et al [7] & Haryana & $2002-06$ & 5849 & 0.3 \\
\hline Naskar et al [8] & Kolkata & $2002-12$ & 128119 & 0.28 \\
\hline Pallavi et al [9] & Mysore & $2004-08$ & 39,060 & 0.44 \\
\hline Patel et al [10] & Gujarat & $2007-13$ & 15,368 & 0.14 \\
\hline Sastry Jayagowri et al [11] & Pune & $2008-13$ & 13,078 & 0.28 \\
\hline Kumar et al [12] & Central India & $2009-11$ & 10,582 & 0.53 \\
\hline Present study & Central Karnataka & $2005-09$ & 19,413 & 0.50 \\
\hline
\end{tabular}

Window period infections, which are missed by immunoassay testing, are responsible for TTI. Nucleic acid amplification testing (NAT) shortens this window period from 22 days to 11 days, thereby offering much higher sensitivity for detecting viral infections [13] Therefore, NAT should be routinely followed in all blood banks, along with switching to $100 \%$ voluntary blood donations.

\section{Conclusion}

Seroprevalence detected by immunoassay testing represents only tip of the iceberg, the real burden may be reduced by newer methodology like NAT.

Ensuring 100\% voluntary blood donations, strict and effective screening programs, effective and efficient use of blood and its components are necessary to control spread of infection through transfusion.

\section{Funding: Nil, Conflict of interest: Nil \\ Permission from IRB: Yes}

\section{References}

1. John TJ. Towards zero transmission of HIV through blood transfusion. Indian J Med Res. 2011 Dec;134(6):746-8.

2. Rodrigo C, Rajapakse S. Current status of HIV/AIDS in South Asia. J Glob Infect Dis. 2009 Jul;1(2):93101. doi: 10.4103/0974-777X.56249.

3. Pagaro PM, Pandit DP, Patel AR, Chaudhari U. Seroprevalence of human immunodeficiency virus in voluntary blood donors: Declining trend. Med J DY Patil Univ 2013; 6(3): 236-9.

4. Ekadashi R, Langer S. Seroprevalence of Human Immunodeficiency Virus and Syphilis in Blood Donors of Delhi. Indian Journal of Medical Microbiology 2009; 27(2): 167-168.
5. Giri PA, Deshpande JD, Phalke DB, Karle LB. Seroprevalence of transfusion transmissible infections among voluntary blood donors at a tertiary care teaching hospital in rural area of India. J Family Med Prim Care. 2012 Jan;1(1):48-51. doi: 10.4103/22494863.94452 .

6. Pahuja S, Sharma M, Baitha B, Jain M. Prevalence and trends of markers of hepatitis $\mathrm{C}$ virus, hepatitis $\mathrm{B}$ virus and human immunodeficiency virus in Delhi blood donors: A hospital based study. Jpn J Infect Dis. 2007 Nov;60(6):389-91.

7. Arora D, Arora B, Khetarpal A. Seroprevalence of HIV, HBV, HCV and syphilis in blood donors in Southern Haryana. Indian J Pathol Microbiol. 2010 Apr-Jun;53(2):308-9. doi: 10.4103/0377-4929.64295.

8. Naskar S, Nandy S, Basu K, Basu R. Study of seroprevalence of HIV, Hepatits B and C and Syphilis among blood donors in a tertiary care hospital, Kolkata. IOSR Journal of Dental and Medical Sciences 2013; 11(3): 63-66.

9. Pallavi P, Ganesh CK, Jayashree K, Manjunath GV. Seroprevalence and trends in transfusion transmitted infections among blood donors in a university hospital blood bank: A 5 year studyIndian J Hematol Blood Transfus. 2011 Mar;27(1):1-6. doi: 10.1007/s12288010-0047-x. Epub 2010 Dec 14. 
10. Patel PJ. Transfusion transmissible infections in blood donors: A 7-year study in central Gujarat. Med J DY Patil Univ 2014; 7: 620-4.

11. Sastry Jayagowri M, Agawane Shubhangi U, Harke Vimal A. Retrospective study of the five-Year Prevalence and trends of transfusion transmitted infections (TTIs) among blood donors at a charitable hospital blood bank in Pune, India. International J. of Healthcare and Biomedical Research 2014; 2(3): 193200.

\section{Research Article}

12. Kumar A, Sharma SM, Ingole NS, Gangane N. Seroprevalence of Transfusion Transmissible Infections (TTIs) among blood donors in a tertiary care hospital, central India: A prospective study. Muller J Med Sci Res 2014; 5: 113-6.

13. Chigurupati P, Murthy KS. Automated nucleic acid amplification testing in blood banks: An additional layer of blood safety. Asian J Transfus Sci. 2015; 9(1): 9-11.

\section{How to cite this article?}

Dr. Bommanahalli BP, Dr. Karani A, Dr. Umapathy KG, Dr. Shashikala P, Seroprevalence of Human Immunodeficiency Virus infection among blood donors of central Karnataka. J Path Micro 2015;1(1):3-7.doi: 10.17511/jopm.2015.i01.02 